\title{
CONEXÓES ENTRE PATRIMÔNIO E SACRALIZAÇÃO DA VIDA DOMÉSTICA: UMA RELEITURA DE O SAGRADO NA VIDA COTIDIANA, DE MICHEL LEIRIS
}

Paola Lins de Oliveira ${ }^{1}$

\begin{abstract}
Não importa que a tenham demolido: A gente continua morando na velha casa em que nasceu.

Mário Quintana
\end{abstract}

Em diferentes momentos da minha recente trajetória acadêmica recorri ao texto $O$ sagrado na vida cotidiana, de Michel Leiris. O primeiro contato, no mestrado, ajudou-me a refletir sobre os repertórios agentivos da artista performática carioca Márcia X., que se dedicou a discutir temas do imaginário doméstico feminino e infantil, do cotidiano, da sexualidade, da religiáo, da vida e da morte. Já no doutorado, retornei ao texto para explorar as múltiplas possibilidades de compor e recompor, num exercício de "distinção de minúcias", a face humana, tema estrutural da obra do artista plástico francês Henri Matisse. A pesquisa de pós-doutorado que desenvolvo atualmente, sobre solicitaçóes de tombamento de bens religiosos indeferidas pelo Iphan, coloca em questão a recusa em conceder lugar a certos exemplares do patrimônio religioso no panteão da herança cultural da nação. Mais uma vez está em jogo uma dinâmica de classificação, e no limite de "distinção de minúcias”, porém há ainda um outro ponto sobre o qual o sagrado cotidiano nos ajuda a pensar: trata-se da própria ideia de patrimônio e sua dimensão de domesticidade.

Uma possível genealogia imprecisa da ideia de patrimônio remontaria aos pertences de indivíduos que, com o passar do tempo, ganham status de posses "representativas" do grupo social do qual são membros.

1 Doutora em Antropologia PPGSA/IFCS/UFRJ. Pesquisadora de Pós-Doutorado PNPD/ CAPES PPCIS/UERJ. Contato: paolalins@gmail.com

Debates do NER, Porto Alegre, Ano i 8, N. 3 I, P. I I3-I23, JAn./Jun. 20 I 7 
De uma forma ou de outra, estes bens fazem o percurso de (alguma) casa para a rua. Nem todas as propriedades consideradas patrimônio realizam esse deslocamento material e simbólico, mas alguns autores mencionam, ainda que superficialmente, o modo como a noção de patrimônio desponta enquanto um bem herdado a ser compartilhado para a posteridade e continuidade dos seus herdeiros e seus modos de vida. Choay inicia sua obra já clássica sobre a mundialização do fenômeno patrimonial da seguinte forma:

Patrimônio ['Bem de herança que é transmitido, segundo as leis, dos pais e das mães aos filhos', Dictionnaire de la langue française de É. Littré]. Esta bela e antiga palavra estava, na origem, ligada às estruturas familiares, econômicas e jurídicas de uma sociedade estável, enraizada no espaço e no tempo (2006, p. 11).

Patrimônio como o legado espacial e temporal da casa, enquanto entidade familiar, a ser transmitido para as geraçóes futuras. Para alguns autores, essa origem doméstica do patrimônio está no cerne da sua conexão com uma força sacralizante que atuaria como um vetor de transfiguraçáo dos usos e sentidos banais de determinados objetos. Parece-me que é sobre o mesmo conjunto de questóes que Chastel e Babelon se ocupam quando afirmam:

em todas as sociedades, desde a pré-história, [...], o sentido do sagrado intervém convidando a tratar certos objetos, certos lugares, certos bens materiais, como escapando à lei da utilidade imediata. A existência de lares familiares, a do palladium da cidade, provavelmente deve ser recolocada na origem ou na base do problema do patrimônio. É preciso aproximar seu destino do de certos objetos comuns, armas e joias, e mesmo edifícios, que, por diversas razóes, escaparam da obsolescência e da destruição fatal para serem dotados de um prestígio particular, suscitar uma ligação apaixonada, até mesmo um verdadeiro culto (Babelon; Chastel, 1994, p. 11-12 apud Fonseca, [1997] 2009, p. 54)

É interessante notar que o sagrado cotidiano de Leiris irrompe nos mesmos objetos citados por Babelon e Chastel: o revólver paterno Smith \& Wesson de tambor, guardiáo da casa, a niquelaria protegendo as joias e o tesouro familiar, entre outros. Para Babelon e Chastel, tais objetos domésticos 
passam por um deslocamento de sentido ganhando um prestígio particular que finalmente levará ao seu culto. Seria então o prestígio de Babelon e Chastel sinônimo do sagrado de Leiris?

Em parte, sim. O prestígio e o culto apaixonado compóem uma dimensão do sagrado de Leiris. Assim como o exercício de distinção de detalhes sutis e a revelação de algo total ou parcialmente secreto. Muito embora o autor esteja falando de um sagrado "fora do âmbito do que constitui atualmente o sagrado oficial (religião, pátria, moral)” (Leiris, [1938] 1995, p. 103), é possível identificar, nos discursos sobre as origens domésticas do patrimônio, um movimento de derivação do sagrado público (oficial, para Leiris) a partir de um sagrado doméstico. Ou seja, estou apostando que entre o sagrado doméstico e o público há mais pontos de contato do que rupturas. Essa linha de pensamento não compromete um dos principais argumentos da reflexão de Leiris, pelo contrário, pretende estendê-lo para a dimensão pública. Esse argumento seria o de que o sagrado, além do fascínio reverente, também inspiraria temor repulsivo. Assim, o sagrado patrimonial de Babelon e Chastel corresponderia a apenas uma das dimensóes do sagrado de Leiris.

A ausência da dimensão repulsiva dificulta o reconhecimento do caráter ambíguo do sagrado. Nos termos propostos por Leiris e por outros autores reunidos em torno do grupo de intelectuais intitulado Collège de Sociologie, principalmente Georges Bataille e Roger Caillois, tal ambiguidade permitiria ampliar o escopo de implicaçôes do sagrado para além de sua heterogeneidade absoluta em relação ao profano, ressaltando suas dimensôes perigosas e impuras.

Desse modo, se estendêssemos o sagrado "puro" do âmbito da casa para o espaço público, provavelmente produziríamos uma leitura durkheimiana da relação entre patrimônio, domesticidade e sagrado, resolvendo a equação a partir da fórmula que reconhece a sociedade como objeto último de qualquer prática sacralizante, de modo que o espaço doméstico traduziria o ambiente seminal do social, ou seja, a família seria sua entidade nuclear primordial. Resumidamente, sacralizar a família seria sacralizar a entidade mínima do social. 
Se Durkheim já mencionava o caráter ambivalente do sagrado religioso, distinguindo seus atributos de pureza e impureza, os autores do Collège de Sociologie exploram tal pista até as últimas consequências e principalmente para além dos limites da imbricação direta entre religião e sagrado. Nesse processo, o sagrado passa a ser percebido como uma força incessantemente intercambiável e dotada de transmutabilidade. Lançar mão dessas reflexões não significa recusar a sacralização do lar (mesmo como "resumo condensado do social"), mas atentar para seus traços ambíguos (sentidos positivos e negativos, atraentes e repulsivos etc.) e não necessariamente religiosos.

Continuando a exploração das características do sagrado doméstico, retomo o comentário de Babelon e Chastel sobre a posição fundamental do lar familiar nas reflexóes sobre o patrimônio. Ao procurar as origens etimológicas da palavra lar, encontramos

Lar: do latim, lar, "o Lar da família (deus da lareira, objeto de culto em casa; o pater famílias oferecia-lhe sacrifícios em datas importantes do mês e em circunstâncias solenes); os Lares também exerciam a sua proteção fora da casa; fig., o lar, a casa, a residência” (Machado, 1959, p. 1300).

O Lar emerge como um deus doméstico, materializado na lareira, fonte de calor, ao qual se rende culto familiar. Um lastro histórico dessa associação pode ser encontrado na Grécia antiga, onde a lareira encarna a deusa Héstia. Situada no meio do grande salão grego (mégaron), a lareira possui forma arredondada e marca o centro do ambiente doméstico; "fixada no solo, a lareira circular é como que o umbigo que enraíza a casa na terra” (Vernant, 1990, p. 152). Enquanto deusa do lar, Héstia desempenha o papel feminino de acolher e zelar pela família, sobretudo do ponto de vista da linhagem geracional. Ela é responsável por garantir a perenidade do grupo doméstico no tempo na medida em que, isentando-se dos deveres sexuais do casamento com um homem estranho, permanece virgem em seu lar de "origem" garantindo a fertilidade e crescimento "dos seus". Desse modo, "a linhagem familiar se perpetua e se mantém semelhante a si mesma, como se, em cada nova geração, nascessem diretamente 'da lareira' os filhos legítimos da casa” (Vernant, p. 158-159). O paradoxo da fecundidade dissociada 
das relações sexuais se "resolve" então potencialmente na elaboração de um repertório mítico em torno dos "filhos da lareira", crianças nascidas diretamente da lareira doméstica, forjadas da terra familiar no forno da lareira.

Lareira, fertilidade, forno. Nessa linha, Vernant sublinha ainda o caráter sagrado das tarefas de produção e partilha do alimento ligadas à Héstia no ambiente doméstico. Para Leiris, a sacralização da lareira passa por outros caminhos. Na verdade, nem mesmo a lareira mencionada pelo autor pode ser considerada uma "verdadeira lareira". Trata-se de uma salamandra, espécie de forno de metal móvel que, disposto em um cômodo, funciona como um aquecedor ativado por carvão.

Figura 1 - Propaganda da salamandra em ferro, marca La Radieuse, catálogo de $1900^{2}$

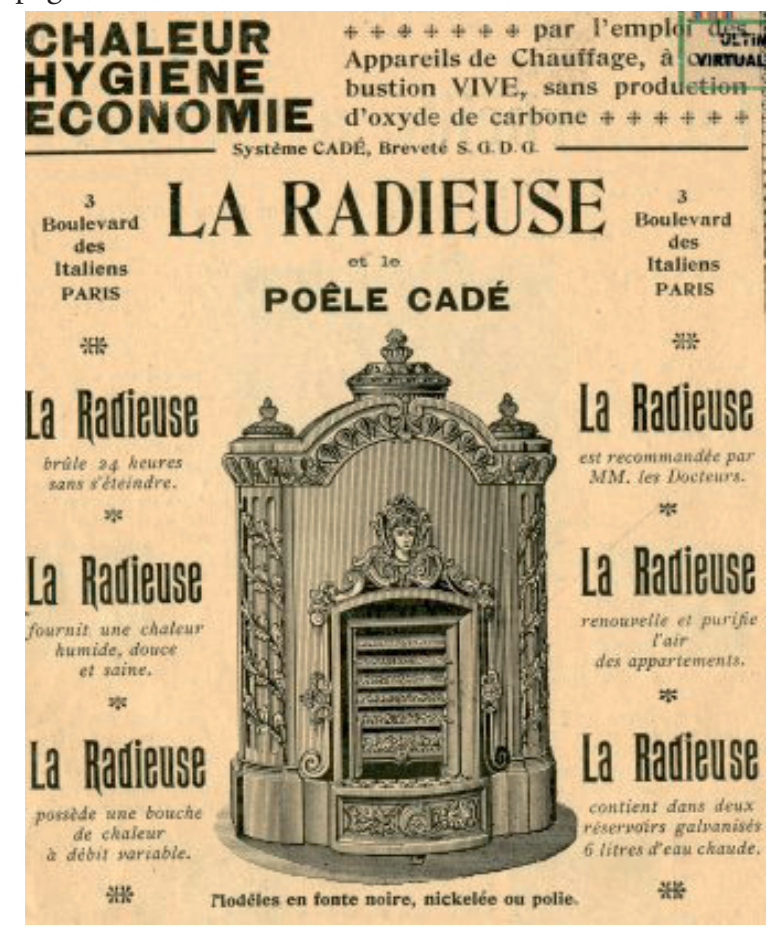

2 Imagem retirada do museu virtual do aquecimento Ultimheat. Disponível em: <http:// www.ultimheat.com/section2-2\%28FR\%29.html>. Acesso em: 23 mar 2016. 
Considerada um "ídolo" de sua infância, a salamandra provocava em Leiris e em seus irmãos sentimentos ambíguos misturando desejo de aproximação e medo, apego e temor, atitudes que marcam o contato com uma coisa considerada ao mesmo tempo prestigiosa e rejeitada, uma "[...] mistura de respeito, desejo e de terror que pode passar pelo sinal psicológico do sagrado" (Leiris, [1938] 1995, p. 102-3).

Em uma de suas autobriografias, A Idade Viril ([19463] 2003), Leiris recua inúmeras vezes ao período da sua infância - recorte temporal onipresente no "Sagrado na vida cotidiana". Em uma dessas digressóes, ele relata alguns episódios que aconteceram em torno da salamandra, elaborados sob o subtítulo "Gênio do Lar". Um dos mais marcantes, e que depois passa a acontecer com certa frequência, envolve Leiris acometido por uma "falsa difteria" no meio da noite, e sua mãe às voltas com os espasmos e tosses do rebento:

Levavam-me à sala de jantar e minha mãe punha-me sobre seus joelhos, ao lado da salamandra que chamávamos 'Radiosa', nome de sua marca de fabricação. Sempre crepitante do ardor de carvão, a 'Radiosa' era flanqueada de dois longos reservatórios de água, cada um podendo conter uma dezena de litros cuja evaporação, sob a influência do calor, atenuava a secura da atmosfera; a imagem de mulher que havia no centro - clássica efígie do gênero República - justificava o nome feminino 'Radiosa' e fazia do engenho uma personificação do fogo doméstico (Leiris, p. 63).

A salamandra aparece portanto como uma substituta da lareira enquanto fogo doméstico, ocupando o mesmo lugar que a deusa feminina do lar, encarnada na figura laica da efígie republicana. Leiris comenta ainda que seus irmãos e ele sabiam que poderiam se queimar caso se aproximassem muito da Radiosa, mas mantinham-se sempre no limite para desfrutar do seu calor.

3 Publicada portanto oito anos após a primeira apresentação do texto O sagrado na vida cotidiana. 
Essa relação com a salamandra doméstica se multiplicava em outros diversos episódios, lugares e coisas que de alguma forma eram proibidas e prestigiosas em seu mundo infantil: a cartola e a supramencionada arma de fogo (Smith e Wesson), sinais da autoridade paterna; o referido porta-níqueis (porte-or) como mantenedor financeiro da existência familiar; o quarto dos pais, palco de acontecimentos noturnos importantes; o banheiro e o mundo subterrâneo acessado através da privada, onde se trocavam "mitologias e hipóteses sobre as coisas sexuais" (Idem, p. 117).

Devoção doméstica, devoção pelo doméstico. Um sobrevoo panorâmico sobre o tópico do culto doméstico e dos ancestrais permite identificar uma preocupação de longo prazo nas ciências sociais, principalmente na antropologia, com o modo como essas práticas fazem parte dos sistemas de parentesco. Cultuar os antepassados e erguer altares domésticos na intenção dos mortos familiares desempenham um papel importante na produção (e reprodução) da sociabilidade em sociedades pré-colombianas, africanas, chinesas, japonesas, entre outras (Bloch, 2002; Fabian, 2005).

Em uma reflexão sobre as relaçóes entre religião e família no contexto fluminense, Luiz Fernando Dias Duarte (2006) mostra a atualidade do culto doméstico enquanto dispositivo de sacralização da vivência, memória e destino da parentela. A performance cultual familiar envolve uma série de sacra, materialidades vinculantes do sagrado, que variam muito (sobretudo em termos de classe) podendo incluir desde bens imóveis, residências, monumentos públicos, até acervos fotográficos, joias, relógios, livros de receita etc. Para Dias Duarte, tais "objets de vertu" são portadores do "mana familiar” (Idem, p. 24) e sustentam os sentimentos de comunhão, reverência e intensidade, que são pilares do reconhecimento de uma dimensão sagrada da vida familiar. $\mathrm{O}$ autor faz ainda uma distinção entre patrimônio físico (posses materiais, objetos, coisas) e patrimônio moral (características de caráter, personalidades, condutas éticas) familiar. Entretanto, sublinha o fato de que embora tais patrimônios se diferenciem, na maior parte das vezes, não são totalmente indissociáveis; havendo mesmo relaçôes de interdependência entre heranças moral e física. Um outro ponto impor- 
tante desta "hagiografia privada" levantada por Dias Duarte diz respeito ao caráter oculto (secreto) de parte considerável desses bens, conservados em locais pouco frequentados, "como relíquias num sacrário" (Idem, p. 24). Sua exposição e revelação acontece em situações críticas, sobretudo em momentos de transmissão do legado diante da morte dos ascendentes "guardióes da memória". Momentos esses que contém o risco iminente da perda da memória, de ruptura no sentido da linhagem parental. Estaria aqui em jogo uma espécie de "retórica da perda" (Gonçalves, 1996) ${ }^{4}$ envolvendo o patrimônio familiar em uma aura sagrada?

Se Leiris esmiúça um sagrado íntimo que se espraia para além de uma derivação do religioso (como santos católicos em um altar doméstico podem expressar contornos institucionais em uma prática local), Dias Duarte também examina sacralizaçôes que extrapolam o religioso, como no caso dos sacra de família. É interessante notar, porém, um certo movimento de "radicalização" de Leiris ao se concentrar em materialidades, tais como o revólver, o banheiro, o porta níqueis etc. que exibem uma espécie de mácula, que os liga a sentidos tomados como negativos da vida social: a morte, o dinheiro, as necessidades sexuais e fisiológicas. Nesse caminho, Leiris enfatiza que o sagrado reverente e "puro" não existe só: ele se irmana a um impuro, aflitivo e violento.

A literatura sobre o culto doméstico também atenta para uma dimensão agonística de suas práticas ao destacar o caráter ambivalente do poder dos antepassados. Para Fabian, "[...] tão propensos a punir, quanto a recompensar, eles oferecem segurança e conforto ao mesmo tempo em que contribuem para a incerteza” (2005, p. 71). Já Bloch afirma que em alguns casos cultuar os antepassados parece "tanto uma questão de honrar os mortos quanto de

4 Gonçalves nos mostra que a perda é inerente ao patrimônio, pois faz parte das "estratégias discursivas de apropriação de uma cultura nacional. É tão somente na medida em que existe um patrimônio cultural objetificado e apropriado em nome da nação, ou de qualquer outra categoria sociopolítica, que se pode experimentar o medo de que ele possa ser perdido para sempre" (1996, p. 89).

Debates do NER, Porto Alegre, ANo i 8, N. 3 I, P. I I 3-I 23, JAN./Jun. 20 I 7 
separar os ancestrais do mundo dos vivos onde eles podem causar problemas" (2002, p. 67). Na mesma linha, Dias Duarte se refere ao toque de "cultos negativos" que incide sobre determinadas práticas cultuais familiares, "por não consistirem apenas na solar fruição da intensidade da comunhão e da reverência, mas por importarem na atualização de dor e sofrimento" (Idem, p. 27), sobretudo em torno da experiência do sacrifício.

A partir deste percurso, emergem algumas linhas que conectam os pontos de heranças veneradas para além do seu sentido eclesial; heranças laicas, a princípio ordinárias, mas que se revestem de um sentido de conexão com uma origem familiar, grupal, enfim, social. Não se trata apenas de desdobrar um sagrado público regional e nacional, a partir do sagrado íntimo, local. A ideia é também chamar a atenção para o modo como o sagrado cotidiano e ambíguo de Leiris possui um vínculo familiar, o qual se conecta com a ideia pública de patrimônio. Daí, caberá aprofundar os possíveis efeitos de contágio dessa ambiguidade, ampliada ao patrimônio público. A aposta aqui é a de que embora Leiris não pretendesse nos falar do sagrado oficial, talvez este seja mais vinculado ao sagrado informal, cotidiano, "pessoal" do que o autor francês gostaria de acreditar.

Há ainda um comentário a respeito da ideia de tempo em jogo nessas reflexôes sobre herança/patrimônio familiar e social, a partir de uma pista extraída dos dados de Dias Duarte. Quando o autor menciona uma fala de campo, na qual uma senhora afirma ter identificado o espírito reencarnado de sua mãe em sua neta, revela-se uma percepção circular da vida social em um contexto contemporâneo. Nesse sentido, assim como a herança familiar, o patrimônio contém uma percepção circular do tempo na modernidade, constituindo uma espécie de contraponto valorativo/simbólico ao tempo (supostamente) linear (ascendente) presente em uma leitura genérica da experiência moderna. Contrapondo o tempo de ruptura que, na modernidade, segue adiante superando tudo, os patrimônios familiar e social expressam uma noção de tempo circular que traz o passado em ondas de memória atualizada em objetos, edificaçóes, monumentos, (constantemente re)estabelecendo o sentido de continuidade. Não se trata aqui evidentemente de 
atualizar distinçóes estéreis entre sociedades e contextos de estagnação e de mudança, a partir de modelos de tempo cíclicos e lineares, mas de sublinhar a variabilidade e concomitância de modelos diferentes de tempo em jogo num mesmo fenômeno.

Finalmente, gostaria de esclarecer que tais reflexóes aparentemente etéreas e ainda preludiais foram motivadas pela minha necessidade de lidar com casos específicos de solicitação de tombamento, envolvendo esculturas (majoritariamente privadas/domésticas) e túmulos. Nesse sentido, o esforço é pensar como tais exemplares singulares, particulares (e muitas vezes privados) extrapolariam (ou não) seu sentido local para um âmbito mais amplo, no limite, nacional. É nessa direção que as reflexôes estão avançando.

\section{REFERÊNCIAS}

BLOCH, Maurice. Ancestors. In: BERNARD, A.; SPENCER, J. (Ed.). 2002. Encyclopedia of social and cultural anthropology. London/New York: Routledge.

CHASTEL, André; e BABELON, Jean Pierre. La notion de patrimoine. Paris: Éditions Liana Levi, [1980] 1994.

CHOAY, Françoise. A alegoria do patrimônio. São Paulo: Estação Liberdade/ Unesp, 2006.

DIAS DUARTE, Luiz Fernando. O Sacrário Original. Pessoa, família e religiosidade. Religião e Sociedade, v. 26, n. 2, p. 11-40, 2006.

FABIAN, Stephen. Ancestor Worship. In: HOROWITZ, M. C. (Ed.). New Dictionary of the History of Ideas. Farmington Hills: Thomson Gale. Vol. I, 2005.

FONSECA, Maria Cecília Londres. O Patrimônio em processo: trajetória da política federal de preservação no Brasil. Rio de Janeiro: Editora UFRJ, [1997] 2009. 
GONÇALVES, Reginaldo. A retórica da perda: os discursos do patrimônio cultural no Brasil. Rio de Janeiro: Editora UFRJ/IPHAN, 1996.

LEIRIS, Michel. Le sacré dans la vie quotidienne. In: HOLLIER, D. (Org.). Le Collège de Sociologie. Paris: Gallimard, [1938] 1995. . A Idade Viril. São Paulo: Cosac Naify, [1946] 2003.

MACHADO, José Pedro. Lar. Dicionário etimológico da língua portuguesa. Lisboa: Editorial Confluência, 1. ed., v. 2, 1959.

VERNANT, Jean-Pierre. Héstia-Hermes. Sobre a expressão religiosa do espaço e do movimento entre os gregos. In: Mito e pensamento entre os gregos. Rio de Janeiro: Paz e Terra, 1990.

Recebido em: 10/12/2016 Aprovado em: 20/02/2017 
